\title{
ABORIGINAL MATHEMATICAL CONCEPTS : \\ A CULTURAL AND LINGUISTIC EXPLANATION \\ FOR SOME OF THE PROBLEMS*
}

Barbara J. Sayers

\section{RELATIONSHIP BETWEEN LANGUAGE AND CULTURE}

In the day-to-day dialogue between Aboriginals and white Australians there are frequent misunderstandings. Sometimes these are plainly linguistic in nature with the Aboriginal not being able to understand English or to express himself clearly in English. But this is not always the case. Frequently the White argument and the Aboriginal argument are like parallel lines of a train track running along together but never meeting. A concept such as that of 'viable industries', which I have tried to explain, can be so foreign to Aboriginals that it is almost impossible to convey it adequately to the community. As one bright young Wik-Mungkan said to me at a community meeting, "Explain it if you can!" In these cases it is often not the language itself that is not understood, but the underlying concepts that the language is expressing. I have been in the same situation in the Wik-Mungkan community at Aurukun. I have understood what was said in terms of understanding the linguistic aspects of the language, but I have not understood the message they encoded. Such messages were incomprehensible because I did not understand the presuppositions on which they were built, nor the Aboriginal concepts which were involved. To sum up, I could understand what was said but not what was meant.

The misunderstandings that develop in such cross-cultural communication are related largely to the underlying values and concepts that each party holds - and holds at a subconscious rather than a conscious level.

Language is spoken by social man, or as Saussure put it, "Language is a social fact". That is, language is spoken in a social

Preliminary paper, reproduced with permission from Work Papers of $S I L-A A B$, Series $B$ Volume 8 - Language and Culture. S. Hargrave (Ed.) Summer Institute of Linguistics, P.O.Berrimah, N.T. 5788. An earlier draft of this paper was read at the sixth Annual Congress of ALAA, Canberra, August 1981. 
context and is used in that social and cultural context in a meaningful way in ongoing exchanges with others. The focus is on meaningful. In the familiar social and cultural setting of the mother tongue, normal exchanges are meaningful. The confusion and misunderstandings of cross-cultural communication are absent because the mother tongue adequately meets the communication needs of the speaker. It is also relevant that the speaker not only knows how to say things, but what to say. What he wants to say in that socio-cultural setting is distinctive to that setting and related to it. As Malinowski said in 1923 (1966 reprint, p.307), "A statement in real 1 ife is never detached from the situation in which it is uttered."

\section{RELATIONSHIP BETWEEN MATHEMATICAL LANGUAGE ANח CULTURE}

\subsection{THE DEVELOPMENT OF MATHEMATICAL LANGUAGE}

The history of the development of English mathematical terminology has helped me to recognise how the concepts developed in Western culture and how the language to discuss them followed. Whorf's observation about the effect of the Industrial Revolution on language is appropriate -

In the Middle Ages patterns already formed in Latin began to interweave with increased mechanical invention, industry, trade, and scholastic and scientific thought. The need for measurement in industry and trade, the stores and bulks of 'stuffs' in various containers, the types and bodies in which various goods were handled, standardizing of measures and weight units, invention of clocks and measurement of 'time', keeping records, accounts, chronicles, histories, growth of mathematics and the partnership of mathematics and science, all co-operated to bring our thought and language world into its present form.

$$
\text { (Whorf, 1956:157) }
$$

Halliday (1978:197) also talks about this development in English: "It took English three or four hundred years to develop its register of mathematics, science and technology and they are still developing." In our Western culture a high value is placed on mathsmatical skill. "We count, measure and weigh everything. Our principle idols, such as money and machines, all rest on a pedestal made of figures and calculations" (Vaszolyi, 1976:36). Vaszolyi goes on to say, "For the Aboriginal hunter, however, figures and counting are irrelevant." The Aboriginal hunter had no need to count. As a 
hunter he either had enough or he needed to continue hunting - or if it were too late to hunt he would simply go without.

It seems obvious that there would be gaps in the mathematical terminology of Aboriginal languages when compared with English with its highly developed mathematical concepts - concepts and language that developed over a long period of time, as previously mentioned. Halliday (personal comment) sees the problem of mathematical terminology in Aboriginal languages more in terms of the briefness of time available to develop them than in terms of inability to do so. Traditional Aboriginal culture did not need to count, weigh or measure and as a result did not develop the appropriate concepts or 1 anguage.

\section{WIK-MUNGKAN MATHEMATICAL LANGUAGE}

If we look briefly at the Wik-Mungkan number terms, we can say that the term thonam, 'one', is the only real number with a fixed value. Kucham, usually translated 'two', is not necessarily an exact two. An example of this usage was an Aboriginal preacher who gave his second point, his next second point and then closed with his third point. Ko'alam likewise is frequently translated 'three' but may mean 'four' or a more generalised 'few'. A teacher at Aurukun, Kath Hinchley, (personal comment) told me that thonam, kucham and ko'alam were being taught as the precise numbers 'one', 'two', and 'three' but that sometimes the children used 'ko'alam to mean either 'three' or 'four'. After she had seen the problem, she would remind the children that numbers are a fixed value. The dual pronouns in Wik-Mungkan are a more definite two, e.g. pula 'they dual' or ngala 'we two', or more accurately ' $I$ and you (sg.)', that is, $1+1$.

Other maths-related terminology in Wik-Mungkan includes yot 'lots' and thaa'wantanam 'a vast mob'. As well, both ko'alam and yot can be reduplicated as ko-ko'alam 'a few less than lots' and yot-yotam 'a big mob - less than a vast mob'. The word ma 'hand' is also used with thonam, kucham, ko'alam and yot, making ma'thonam 'once', ma'kucham 'twice', ma'ko'alam 'three or a few times' and ma'yotam 'lots of times'. This is the everyday usage of these terms amongst the Wik-Mungkan today, but older speakers also use ma' 'hand' to roughly indicate five. Ma'yotam, which could be translated 'the whole hand', may be used to indicate five but is also used to roughly represent a week. Likewise, ma'kucham 'two hands' is similarly used to indicate ten, or two weeks.

Tallying methods were also used by the Wik-Mungkan. To indicate when a ceremony would be held, the days would be tallied by turning the fingers down. There are no monomorphemic terms for this, but the 
messenger would turn each finger down and say ma'yinang 'hand like this'. The word tha' 'foot' could also be used. A term roughly equivalent to twenty is ma'yotam tha' thampang 'all the hand and the feet also'. For larger numbers, such as thirty, a second person could be involved, as for example, tha'ngatharam, a' wanch thum ngatharam ma' tha' 'my feet and my wife's hands and feet'. Longer periods of time are also indicated by the moon, such as kep thonam kan'an wanta 'when one moon has passed'. Tallying was apparent1y also done on a message stick. While I have never seen this method used at Aurukun, such usage is widely reported in the literature. J. Harris (this volume)* provides examples of both tallying and non-specific number terms used by other Aboriginal groups.

It is an undisputed fact that terminology can develop in a language when there is a need. I see the problem in Aboriginal languages being that the need is an imposed one. It is outside pressure that makes the concept development necessary - not felt need in the community. For many Wik-Mungkan people precise numbers are not understood, and who in the community at Aurukun would want to talk about fractions or square roots? These terms could be developed by language engineering, or to use a less offensive term, by language planning, but such efforts are hastening the process, as Halliday says :

Developments that took centuries in English and French are expected to happen in ten years, or in one year, or sometimes one month. This requires a high degree of planned language development. I

$$
\text { (Ha11iday, 1978:197) }
$$

The absence of precise Wik-Mungkan terminology is more than simply 'a gap in the inventory of cultural items' as Hale (n.d.) sees it, and I disagree with his statement that 'filling the gap is a rather trivial matter'. Hale bases his statement on his experience with the Warlpiri's handling of money. I cannot say that my experience with the Wik-Mungkan and money has been that simple. Most Wik-Mungkan that I dealt with knew that the name of a purple note was five dollars and that the name of an orange one was twenty, but many did not seem to know that four five-dollar or purple notes were the same value as one twenty-dollar or orange one. Some seemed to buy by the name or the colour of the note and if they had the right one, that was all that mattered, i.e. having the money to pay for

* Work Papers of SIL-AAB, Series B Volume 8 - Language and Culture, 1982.

1 For a discussion on such planned language development see Leeding, 1976, 1977 and 1980) 
something was often more important than whether the item was worth that amount of money. Some Wik-Mungkans, of course, handle money very well, but from talking to others who have worked with Aboriginals, it seems to me that my experience is more likely to be the norm.

Hale would probably agree with Boas (1974:25) who said that some people do not count because they do not want to. I agree with this but feel that it is only part of the answer. The question remains, why doesn't the Aboriginal want to count? I believe the Aboriginal not only doesn't see any value in precise counting, but, particularly in a more traditional Aboriginal environment, he doesn't understand the number concept basic to counting. I base this statement on the following discussion.

\subsection{TRADITIONAL ABORIGINAL WORLD VIEW}

The traditional Aboriginal saw things in terms of specifics rather than generalities. In his world, items such as his spears were unique, each recognised by its individuality. A missing spear would thus be the loss of a particular spear rather than just one of a number of spears. Without mass production producing large numbers of identical spears, it seems quite reasonable that each spear was seen as unique. Such an item in Wik-Mungkan is described as ma' nunga literally 'his hand', but a freer translation would be 'his handiwork', or 'his style'. There is nothing of this individuality about boxes of matches, packets of tea or any other mass-produced item sold in the store. As Boas put it:

It must be borne in mind that counting does not become necessary until objects are considered in such generalized form that their individualities are lost sight of.

(Boas $1974: 25$ )

I would like to look at the reverse of this statement. That is, while objects are seen in such individualised form, it will be very difficult for anyone to abstract number from them and thus be able to count. Boas goes on to say:

For this reason it is possible that even a person who had a flock of domesticated animals may know them by name and by their characteristics without ever choosing to count them. 
This is true about Aboriginals and their dogs. My next door neighbour at Aurukun had many dogs and he knew each one individually, but he had no idea how many he had except to say that he had yot, or a lot of dogs. The police restriction on dog numbers was a constant problem to him. He knew he had too many, but he could never understand the police method of numbering his individual precious dogs, nor could he see how dogs could be kept by number rather than by their individual worth.

Perhaps at this stage I should point out that Aboriginals do generalise. Were this not the case there would be no concept such as kurow 'salmon' or ka'ant 'catfish' or even a more general term like the word for fish. In Wik-Mungkan there is even a still more general term, the term minh, a generic term for all edible protein food meat, fish, eggs. This term applies whether the animal is alive or the egg raw, or whether the protein food is ready to eat. When talking about fish the term minh may be used alone or it can co-occur with the more specific word for fish nga'a, that is nga'a does not usually occur alone. Thus minh nga'a is the generic form for 'fish'. The Wik-Mungkan do classify and generalise, but their classifications are often different from ours, a fact that is more obvious in nounclassifying Aboriginal languages. I would like to point out, however, that the generalisation that leads to such concepts as 'salmonness' could be said to exist in a concrete form, i.e. related to the fish, whereas the concept of number has to be related to a non-concrete property. From this perspective it can be seen that number is a more abstract concept. As I mentioned before, there is a generic word for fish and some Wik-Mungken would tally up a catch of fish by number. But for others the differences would be in focus; so it would be difficult for them to add items that were not seen as 'the same'. For them a tally of fish would be, for example, three salmon, two catfish, and one grunter, rather than a tally of six fish.

Aboriginals, however, abstract other concepts such as 'kangarooness' in a way that is difficult for the white man to understand. This shows that his perception of the universe is different from that of the Whites. While the White is happy to abstract number or colour from various items - for example, to see 'greenness' as the common factor between green leaves, green grass and green frogs - the Aboriginal does not see this, that is, an Aboriginal who has not come into contact with Western education. Likewise, he does not see 'threeness' as the common factor between three blocks, three balls and three toy trucks. On the other hand the Aboriginal sees 'the essence of kangarooness' in the animal kangaroo, the man of kangaroo totem, and the totem place - the aawa in Wik-Mungkan. The white man does not see this relationship and is usually puzzled if not sceptical 
when an Aboriginal refuses to shoot a kangaroo because a man of that totem is missing in the bush. His explanation that he could be shooting his brother seems far fetched. Likewise in mining or oil exploration the idea or hurting the totem animal of that place (i.e. his brother) is frequently rejected as 'rubbish'. But when a notion such as 'kangarooness' is recognised, the Aboriginal position can be understood.

Thus it can be seen that there is a close relationship of culture to language. As I see it, it is quite reasonable to have not only gaps in the mathematical vocabulary, but to have corresponding gaps in the concepts of that culture - concepts which are needed before the vocabulary can be developed.

\section{MEASUREMENT IN WIK-MUNGKAN}

In this section I will be looking at the linguistics of the Wik-Mungkan in Pam Harris' (1980) Measurement in Tribal Aboriginal Communities. Having known Pam Harris for some years I read it with great interest. In looking at the data that she presents - data collected from 22 linguists - some interesting facts emerge. As a result of reading the questions and considering the Wik-Mungkan responses which would be possible in such a situation, it became immediately obvious to me that the material presented in this book is more a compilation of data than an analysis of it. The material presented by the linguists appears to be accepted at face value. This is probably because Harris looks at the data as a teacher rather than as a linguist. (Also many of the respondent's answers appear to be English explanations rather than vernacular examples). Another factor that is immediately evident is that Harris was looking for equivalents to English semantic categories rather than looking to see how Aboriginals themselves discuss measurements.

Harris (1980:49) asks such questions as "Does the language have an abstract term equivalent to the English word such as in

?" She summarises the responses to ten such questions in the following table. (See Table 1)

Table 1

Number of Negative and Positive Answers to Type 1 Questions

\begin{tabular}{|c|c|c|c|c|}
\hline Abstract Term & Yes & No & Abstract Term & Yes \\
\hline Length & 3 & 18 & Speed & - \\
\hline Height & 1 & 19 & Weight & 1 \\
\hline Distance & 3 & 19 & Area & 2 \\
\hline \multirow[t]{2}{*}{ Time } & 7 & 12 & Volume & - \\
\hline & & & Money & 22 \\
\hline
\end{tabular}


In summing up this table Harris says that "with the exception of time and money there are almost no abstract terms referring to the areas of measurement in this study." On this point I agree with her. Regarding the absence of abstract terms, she goes on to say, "It does not imply that Aboriginals are therefore unable to discuss length, height, distance etc. They merely do it in a different way. However, the lack of abstract terms could be an indication that such measures are unimportant in Aboriginal life..."

I agree that these measures are unimportant in Aboriginal 1 ife I would even go so far as to say that they are irrelevant. In discussing length, distance, height etc., Aboriginals discuss them in a very concrete way rather than with the abstract terms referred to in the questionnaire. The Wik-Mungkan answers reveal this. I believe that this is not a mere difference in terminology but a major difference in concept development and is therefore one of the causes of the problems so often experienced in teaching or discussing these areas of applied mathematics.

In considering Aboriginal terms for measurements, a rather obvious question arises: how could an Aboriginal ask a question such as "What length is that?" if he didn't have a number or measurement system with which to reply? Such a question would normally evoke an answer such as "75 cm", "2.4 metres" or some such figure. Of course it would be possible to answer in Wik-Mungkan with a comparative such as "It is long like from here to Charlotte's house." But an answer such as "It is long", with no such qualification would be meaningless. In Aboriginal conception, height, length, breadth etc. are not features that are abstracted. They are an inalienable part of the item under discussion. There is a significant difference in asking "What Zength is this?" (Harris' question) and the question a Wik-Mungkan would ask: "Is this long?" or even "Do you call this long?" These questions show how length, height etc. are specifically related to the item in question.

In the Appendix, I give a possible Wik-Mungkan alternative for the first of Harris' questions on each topic in her questionnaire. As I see it, these examples show a basic difference in the Aboriginal's conception. He can ask, "Maybe this is big, maybe it's small?" or he can ask, "Maybe this is big, maybe it isn't?". In each case he does it by a binary opposition -- either by an antonym or by negation. His language makes use of binary opposition as a means of comparison in many instances, but it proves unsatisfactory to a present day Wik-Mungkan in describing, for example, two men of almost the same height. To say, "Tom is tall, John is short", or "Tom is tall, John is not tall" now fails to satisfy in terms of the preciseness of the 
comparison. These days 'mure' is frequently borrowed and a WikMungkan child will say, Tom more pi'an (big) "Tom is bigger".

It can be seen from these examples that terms used in applied mathematics are not usually abstracted in the Aboriginal's semantic system. As far as Wik-Mungkan is concerned, the 'nearest equivalent' type of data presented in Harris' volume is really something quite different and thus could cause a lot of problems. As with number and colour, special care is needed when teaching these concepts to children. A child would need to have mastered the number system before being able to deal with its application to these measurement concepts.

\section{SOME TEACHING IDEAS}

As someone who is untrained in teaching, especially in mathematics, I am probably asking for trouble; nevertheless I still venture to make some suggestions. These ideas come largely from my own experience at Aurukun prior to 1977, particularly with children in my home.

From my observation, many white teachers of Aboriginal children seem to have only a limited interest in the semantic systems of the child's language; there is also little interest in other mathematical systems in the schools. The obvious example is card playing. These systems will be discussed in relation to teaching 'school' mathematics and then suggestions given for introducing unfamiliar mathematical concepts.

\subsection{CLASSIFICATION SYSTEMS}

Firstly we will look briefly at the child's classifying ability. Wik-Mungkan is not a noun classifying language, but many Aboriginal languages are. Semantic 'sets' can easily be seen in these languages, but even languages without such systems still make classifications which are different from those made in English. For example, in WikMungkan there is the classification of edible protein food -- meat, fish, eggs, versus inedible animals etc. There is a similar distinction between edible plants and inedible. Other items for which there are generic terms, that is classifying terms, are snakes, fish and trees. These give a basic understanding of how the Wik-Mungkan 'cuts up the universe'. Where applicable, noun classes which distinguish various shapes could be used to introduce the notion of shapes. There may or may not be considerable overlap, but the Aboriginal system needs to be recognised and where possible used as a way to move from known to unknown. The white teacher's problem is that he is 
often not aware of the classifications in the vernacular and if he is, it is often difficult to find suitable one-word terms in English for the classifications. He also may have difficulty convincing the education authorities of the validity of his suggestions for classroom use.

\subsection{CARD PLAYING}

Many Aboriginal children play cards from an early age 'gamble' as they call it in Aurukun. While still at Aurukun I briefly observed the children playing cards and I was amazed at the speed with which they came up with the answers. As the children's visual memory and visual discrimination are very good, it seemed to me that their speed was related to their exceptional visual memory, a memory for spatial arrangement or pattern, rather than with their ability to add and calculate - although at least some adults count and calculate.

Davidson (1979) writes of the method of arriving at the score in card games at Bamyili. In the games he describes, the card being identified is covered, apart from the edges, and the pattern is identified in terms of the arrangement of motifs, the top part of the numerical symbol, and slight individual differences in the corner suit identification. This is a lengthy process. Davidson's observations are important because they deal with the method of arriving at an identification of the cards. He sees it not as a matter of number recognition, but more one of pattern recognition. This is the conclusion I had arrived at when I observed the Aurukun children instantly recognised the placement of motifs on each card and also the motif combinations in adding the cards together, judging by the speed with which they arrived at the answers. (There are other accounts of card playing, such as Robinson and Yu 1975 for the Kimberleys, and Holm and Japanangka 1976. for the Centre).

One feature of card playing that seems to be common is that the tens are ignored in score tota1s, e.g. $3+4=7$ but $7+5=2$, the 10 being dropped. So in card playing $3+4$ gives a higher score than $7+5$. The Aurukun children recognised the scores as soon as they saw the cards - before I could add them up! (One Aurukun teacher told me that she has had the same experience.) Another feature is that totals of 10,20 and 30 are considered the same - such a total is necessary from any three of the five cards dealt before a player can score with the other two. Again we see the ignoring of the tens value, the focus being on the zero units. One teacher recently told me that some children could add up before learning to play cards, but then began dropping the tens. Some of these children could add it in when reminded. 
It seems to me that for the Aboriginal card player, a card could be described as a pattern with a name - the 'name' for at least some players having little association with the numerical value of the card. So, for example, a 5 would be seen as a certain pattern, not necessarily related to the 'fiveness of five', or a 3 to the 'threeness of three'. If the card playing child is to achieve in mathematics at school, he needs to know that the two systems are different. He not only needs to learn number recognition skills but he needs to learn the underlying value of each number.

\subsection{TEACHING THE CONCEPT OF NUMBER}

Problems in grasping this notion of 'the threeness of three' are often multiplied for the child who comes to school and is very soon introduced to counting - and with counting, the use of numbers as an index, that is as an address. For example, children are lined up and numbered and then addressed as number 3 , or number 7 . The next day they will be in a different order in the line and will have a different number. Thus the use of numbers as an index reinforces the idea that a number is a name. So it is no wonder that the child is confused when number words are taught as having consistent numerical value.

I would suggest that the use of numbers as an index should be left until after the value of the number words is understood. Omitting counting would be very hard for the teacher who usually teaches counting as the earliest number skill - and of course a pre-school child in our society is considered 'clever' if he can count. The problem arises when a child who can count is assumed to know the numerical value of the number words he has used. Omitting the use of number words in addressing children would probably help the child to grasp that the number was not just a name for the one person or item so numbered but was actually a total of all the numbers that had gone before, e.g. $7=\ldots \ldots$ not $\ldots \ldots$...

\subsection{TEACHING NUMBER AS AN ABSTRACT PROPERTY}

I would suggest that the 'threeness of three' etc. be taught before there is a heavy emphasis on counting. I would further suggest that this be done with introduced mass-produced items that don't have any obvious distinctions. Thus, with obvious distinctions eliminated, the child should be able to generalise enough to abstract number from them. Each traditional item is unique, so it would be harder for the child to generalise if these were used. After all, the need for precise number skills is related to the introduction of Western technology, mass production, trading etc. 
My observation of Aboriginal children is that they do not seem to grasp 'three' as something that can be instantly recognised, whether it be three blocks, three toy trucks or three cans of soft drink - although the cans of soft drink would be recognised first. The relationship of three cans of soft drink to three children is one concrete example that would probably be grasped quickly. (My teacher friend tells me that even this fails sometimes, as cans of drink are passed around and 'lo1ly bars' shared so that no one misses out.)

I would suggest, for example, that three of various items be used until the children can see that the common thing about each group is its 'threeness'. The child should instantly be able to recognise 'three' without having to count each time, e.g. three fingers held up for a brief period, too brief for the child to count. This would be repeated with other numbers until the children learned to associate a number word with a specific number of items - that is with its numerical value. The number symbol would also need to be associated with the numerical value, especially if these symbols are covered in card playing and are not used in recognising the value of the card (Davidson 1979).

While I would suggest that the pattern associated with a particular number be used when first dealing with a particular number, so that the number name, the symbol and the pattern can be associated with the numerical value of the card, I strongly recommend that the child learn that the number name and symbol are not restricted to that particular pattern. The component parts of a particular pattern would need to be manipulated into as many other patterns as possible. My personal experience with children in my home at Aurukun was that this was extremely difficult for them. Once the original or distinguishing pattern was broken they found it difficult to accept that any other arrangement of the same items was, of necessity, the same number. But they need to take this cognitive leap - a leap analogous to that of Piaget's conservation - before they will be able to grasp the intrinsic 'threeness of three' concept.

\subsection{TEACHING BY EXCLUSION}

To help in teaching the concept of number, I also suggest what I call 'teaching by exclusion'. I would take, for example, the number three and say, "This is three, it is only three, it is always three; it is never four, it is never two, it is never ten", etc. As a specific number may be focused on by the teacher for a week or so, maybe 'teaching by exclusion' would help the child to 'remember' this number - that is, he would grasp that it had a fixed (not random) and 
exact value. It was the same from one week to the next. The use of exclusion is an Aboriginal way of defining an item. I have used it very successfully in teaching colours, but I have not had an opportunity to use it for number. I was asked not to suggest it for teaching number in the school as it could interfere with later sophisticated concepts. I would be much bolder today in stressing its value, for without a grasp of basic concepts, how can the more advanced concepts be understood?

For the score of card combinations the same principles apply. The cards are recognised by the pattern combinations and the score could be seen to be more a name than a real numerical value. To see the difference between the two systems - cards and school - the player needs to know that in school, in the White system, it is important to know the intrinsic value of the numbers he uses, both in relation to individual cards and to the card combinations. I would hope that once the numerical value of the individual cards was understood, the whole notion of numerical value related to number names and symbols would also be understood. Thus a player who would see 10,20 or 30 as the same for scoring in cards, would know that these were numerically very different. He would need to know this to understand the tens system, so basic to understanding Western mathematics and money. I know some educated Aboriginals who do not understand the tens system. I saw one man in the store add rapidly across the columns in a zig-zag fashion. He knew all the combinations but his total was way out. There is a need to know that $7+5=12$, a larger number than 7 , the total of $3+4$. Obviously my friend who added in the zig-zag manner didn't know this. His addition of $12+7$ would be 10 , i.e. $1+2+7$, rather than 19 .

Of course some Aboriginals at Aurukun are very good at numbers and handle money, banking, shopping, mail ordering as well as weighing and measuring very wel1. Some, it would appear, also use their number skills in card playing, though for various reasons I have not observed the adults play. However, illiterate Aboriginals who play cards would, I suspect, use the pattern recognition system. I have also observed children who were known poor achievers at school play cards with speed and apparent skil1.

For applied mathematics $I$ believe it is essential that teachers understand the significance of the absence of abstract terms for length, weight, height etc. If there were abstract terms, it would imply the existence of a numerical measuring system. It would also imply a system with fixed or exact units of measurement. ('True' and 'constant' are the terms Holm and Japanangka 1976 use). Before a child can hope to master measuring, for example, he must understand 
that the units of measurement are fixed and exact. The same teaching by exclusion could be helpful here: a centimetre is this long, only this long, always this long, never longer, never shorter. This seems to help remove the concept of uniqueness (and for some the associated concept of randomness), concepts that hinder the ability to understand the fixed and exact nature of measurements. So for applied mathematics the child has to master two systems: firstly the 'threeness of three' concept and then the 'fixed and exact' concept. Once the child has grasped these concepts he should be ready to use centimetres, grams or any other unit of measurement applicable to the task at hand.

\section{CONCLUSION}

As a closing comment I would like to suggest that it is not the use of borrowed terms that causes the problems in Aboriginal understanding of mathematics, but the basic misunderstanding of what these terms mean. This would apply to both number words themselves and also to words such as length, speed, weight, area etc. It a1so applies to units of measurement which must be seen as fixed and exact.

As I have shown, there are cultural and linguistic reasons for the problems encountered in mathematics education. As I see it, unless there is community desire to develop vernacular terminology, as in Anindilyakwa, it would be better if English terms were used and the vernacular left for family 1 ife and traditional interest. This could lead to a stable bilingualism, a much more realistic goal than having Aboriginals able to 'talk about anything under the sun' in both languages, as Hale and O'Grady suggested in 1974. Such a specialised bilingualism without a total overlap of function would be more likely to maintain the Aboriginal vernacular, for if you can 'talk about anything under the sun' in both languages, there soon would be no need for the vernacular.

If an Aboriginal child is going to progress at school he needs to learn the concepts discussed above, and his ongoing mathematical education would need to be in English; so it seems reasonable to introduce the borrowed term with the new concept as it is taught. of course, if the child is to remain a traditional Aboriginal he doesn't need to know. And how 'Aboriginal' he will remain is a very real problem to some educators as well as to some Aboriginals. 
APPENDIX - Wik-Mungkan Alternatives for Questions in Harris 1980

1. What length is this?

In ongk ey

this long quest

'Is this long?'

2. What height is this?

In achantang than ey

'Is this tall?'

3. The distance is shown on the signpost

Signpost alangan waa'an ngant, aak kech nath,

Signpost that (trans)tell us-it to-us place far maybe or nath ya'

or maybe not.

'That signpost tells us whether the place is a long way, or maybe not.'

4. It takes a long time

Aak yaam yump-yumpanak ely

time long for making (doing) Q.

'Does it take a long time to do that?'

5. At what speed did they travel?

Than erkam moi'in ey

They fast ran-they Q.

'Did they run (trave1) fast?'

6. What weight is it?

yuk in anhanh ey

thing this heavy Q.

'Is this thing heavy?'

or

Yuk anan, nath anhanh nath ya' they that maybe heavy maybe not

'Maybe that thing is heavy, maybe it's not.' 
7. What is the area of the 1 and you want?

Nint kaangk aak we'ara pi'-pi'an ey

You like place wide mind-you $Q$

'Do you want to keep a wide piece of land?'

(This is an unlikely question. 'Do you want to keep this wide piece of land?' would be more likely. This type of question would be related to asking about traditional land for land rights, so the land in question would be specific.)

8. Volume

e.g. a block of wood - the only way would be yuk ina pi'an 'This wood is big' or one could ask, nint kaangk yuk pi'an ey, or manya you like log big Q. or small

'Would you like a large or small log?'

Note also that or is borrowed.

Similarly for an amount of water, a rock, an amount of space in a house or other hollow object - all would have to be described in terms of specific items being either large or small.

9. Is there a general term for money?

Wik-Mungkan has the term wukal for a11 money. I do not know the origin of the term. Sometimes a distinction is made, wukal being used for notes and 'cents' for silver. 'Brown cents' are considered to be worthless. Some do not understand that cents make up dollars. (I have had someone refuse to pay me a dollar bill for stamps and let me give them change. Instead they went home and borrowed silver to pay.) 